\title{
EFEITO DA SUBSTITUIÇÃO PARCIAL DO MILHO PELA POLPA CITRICA PELETIZADA NO DESENVOLVIMFNTO E NA QUALIDADE DA CARCAÇA DE SUINOS
}

Velloso, L. et al. - Efeito da substituição parcial do milho pela polpa cítrica peletizada no desenvolvimento e na qualidade da carcaca de suinos. Kev. Fac. Med. vet. Zootec. Univ. S. Paulo, 11:31-42, 1974.

Resumo: Foram utilizados 10 suinos machos castrados, $1 / 2$ e $\$ / 4$ de sangue Landrace $x$ Duroc-Jersey, com peso médio inicial de $21,7 \mathrm{~kg}$. Estudon-se o ejeito da substituiçāo parcial do fubá de milho pela polpa citrica peletizada, no desenvolvimento dos animais $e$ na qualidade de suas carcaças, concluindo-se que até o nivel de $15 \%$, a polpa citrica podera substituir o fuba de milho, sem que ocorra qualquer alteração no ritmo de desenvolvimento ou nas caracteristicas principais da carcaça dos suinos.

Unitermos: Suinos*; Engorda*; Polpa citrica*; Carcaça, qualidade*; Alımentaçăo*.

\section{INTRODUCAO E LITERATURA}

Dos diversos sub-produtos industriais que se obtém após a extração do suco de frutas citricas, destacam-se: a polpa, o melaço e os b́leos das cascas e das sementes, segundo HENDRICKSON \& KESTERSON 6 (1965).

A polpa citrica, de larga aplicação no balanceamento de raçōes para bovinos, também poderá ser utilizada no arraçoamento de suinos desde que sua participaçāo não utlrapasse os $20 \%$ do total da ra- ção. BAIRD \& AMICK ${ }^{2}$ (1966), compararam seis diferentes fontes fibrosas ,no desenvolvimento de suinos da raça Poland-China e os efeitos exercidos pelas mesmas, sobre as características das carcaças. As raçōes continham $7,5 \%$ de fibra bruta, sendo que o tratamento com polpa cítrica proporcionou ganho médio, em peso, diário de $0,700 \mathrm{~kg}$ e conversão alimentar do 3,44 : 1. As mensuraçōes procedidas nas carcaças dos animais apresentaram as seguintes médias: comprimento da carcaça

- Professor Assistente Doutor

* Professor Livre Docente. Departamento de Produçao Animal da Faculdade de Medicina Veterinárla e Zootecnia da USP.

*.. Engenheiro agrónomo - Pesquisador Cientifico do Instituto de Zootecnla da Secretarla da Agricultura, Săo Paulo. 
VELLOSO, L. et al. - Efelto da substituição parcial do milho pela polpa citrica peletizada no desenvolvimento e na qualidade da carcasa de sulnos. Rev. Fac. Med. vet. Zootec. Univ. S. Paulo, $11: 31-42,1974$

$72,6 \mathrm{~cm}$, espessura do toicinho $3,4 \mathrm{~cm} \mathrm{e}$ área do olho de lombo $30,1 \mathrm{~cm}^{2}$.

BAIRD et al. ${ }^{4}$ (1969), trabalharam com 8 lotes de 10 suinos também alimentados com raçōes contendo diferentes fontes fibrosas. Os animais permaneceram no experimento, desde os $18,0 \mathrm{~kg}$ peso vivo até os $91,0 \mathrm{~kg}$, em média. Ensaio de digestibilidade revelou que $66,5 \%$ da fibra e $76,7 \%$ da celulose foram digeridas. O ganho em peso médio diário no tratamento com polpa citrica, foi de $0,680 \mathrm{~kg}$. BAIRD et al. 3 (1971) estudaram o efeito da polpa cítrica na digestibilidade da raçāo e no desempenho dos suinos, usando gordura bovina para manter as dietas isocalóricas. Os tratamentos continham, $0 \%, 10 \%, 20 \%$ e $40 \%$ de polpa cítrica, tendo apresentado ganhos em peso, médios diários de 0,790 $\mathrm{kg}, 0,730 \mathrm{~kg}, 0,750 \mathrm{~kg}$ e $0,620 \mathrm{~kg}$ respectivamente. As conversōes alimentares foram 3,$38 ; 3,23 ; 3,08$ e 3,40 para os diversos niveis de polpa. A análise estatistica revelou diferença significativa apenas para o nivel de $40 \%$, com relaçāo aos ganhos em peso; contudo, as carcaças não apresentaram qualquer diferença significativa. Com as raçōes mantidas isocalóricas, a polpa cítrica substituiu o milho nos níveis de $10 \%$ e $20 \%$ com vantagem econômica e sem alterar o ritmo de desenvolvimento ou a qualidade da carcaça. Também não foram constatadas diferenças marcantes quanto às digestibilidades da matéria seca, da proteina bruta e da fibra bruta.

BAIRD et al. 1 (1972) também usaram niveis de $0 \%, 10 \%, 20 \%$ e $40 \%$ de polpa citrica em rações para suínos, até $95,0 \mathrm{~kg}$ de peso vivo. Gordura bovina foi adicionada para equiparar os teores energéticos das dietas. As médias diárias de ganhos em peso foram $0,800 \mathrm{~kg}, 0,740 \mathrm{~kg}, 0,720$ kg e $0,630 \mathrm{~kg}$ e as conversões alimentares 3,$24 ; 3,10 ; 3,06$ e 3,13 respectivamente, para cada nivel de polpa citrica. Houve diferença estatística significativa entre $0 \%$ e os demais niveis para as variáveis mencionadas. Os teores de $10 \%$ e $20 \%$ de polpa corresponderam a $97 \%$ e $96 \%$ do valor do milho, enquanto o teor de $40 \%$ de polpa correspondeu a apenas $82 \%$ do valor do milho.

KRONKA ${ }^{7}$ (1972) num trabalho em que estudou o efeito da adiçāo de gordura bovina para suinos, machos castrados, da raça Duroc-Jersey, de peso entre $26,0 \mathrm{~kg}$ e $95,5 \mathrm{~kg}$, encontrou os seguintes resultados, para raçāo contendo $16,03 \%$ de proteina bruta, $5,20 \%$ de fibra bruta e 3.300 Kcal de energia digestível/kg : ganho em peso/ dia $0,734 \mathrm{~kg}$, conversão alimentar 3,57 , rendimento de carcaça $75.7 \%$, comprimento da perna $56,7 \mathrm{~cm}$, áreo do olho de lombo $24,2 \mathrm{~cm}^{2}$ e espessura do toicinho $3,9 \mathrm{~cm}$. SMITH \& CARPENTER 10 (1973), avaliaram os fatores associados com a composiçāo de carcaças de suínos, estabelecendo o desvio padrāo de cada medida estudada, a saber: comprimento de carcaça (cm) $75,64 \pm 2,21$; espessura de toicinho $(\mathrm{cm})$ $3,48 \pm 0,46$; área do olho de lombo $\left(\mathrm{cm}^{2}\right)$ $28,20 \pm 3,42$; rendimento de cortes cárneos (\%) 44,82 $\pm 3,74$ e rendimento de gordura (\%) 42,87 \pm 4,42. Finalmente. CUNNINGHAM et al. 5 (1973) encontram as seguintes medidas nas carcaças de suínos machos castrados: comprimento de carcaça $76,4 \mathrm{~cm}$, espessura de toicinho 3,9 $\mathrm{cm}$, área do olho de lombo $26,3 \mathrm{~cm}^{2}$.

\section{MATERIAL E MÉTODOS}

Foram utilizados 10 suinos, machos castrados, $1 / 2$ e $3 / 4$ de sangue Landrace $x$ Duroc-Jersey, com peso médio inicial de $21,7 \mathrm{~kg}$ e idade variando de 2 a 3 meses, ao início do experimento. O delineamento experimental adotado foi o de blocos ao acaso, com dois tratamentos e cinco parcelas, segundo STEEL \& TORRIE 11 (1960). Os animais permaneceram em baias individuais, sendo pesados cada 14 dias, sempre com jejum de 16 horas. $O$ controle 
VELLOSO, L. et al. - Efelto da substitulçăo parclal do milho pela polpa citrica peletizada $\mathbf{n}$ desenvolvimento e na qualidade da carcaca de suínos. Rev. Fac. Med. vet. Zootec. Univ S. Paulo, 11:31-42, 1974.

de consumo das raçōes fol feito individualmente. As raçбes experimentais constantes da Tabela I, foram balanceadas para encerrarem os mesmos teores de proteina bruta ( $P B$ ) e energia digestivel (ED). O experimento fol dividido em duas fases segundo a Fase I levada até que os animais de um dos tratamentos atingissem péso médio de $55,0 \mathrm{~kg}$ e a Frase $I I$ at $95,0 \mathrm{~kg}$.

As modificaçס̄es introduzidas de uma pa. ra outra fase, constaram tăo somente dc balanceamento de novas raḉes, para atender as exigencias nutricionais dos sulnos, segundo recomendaçס̄es do NRC: (1968).

TA BELA I

Raços experimentais.

\begin{tabular}{|c|c|c|c|c|}
\hline \multirow{3}{*}{ Ingredientes } & \multicolumn{2}{|c|}{ Fase I } & \multicolumn{2}{|c|}{ Fase II } \\
\hline & \multicolumn{2}{|c|}{ Até $55,0 \mathrm{~kg}$ peso vivo } & \multicolumn{2}{|c|}{ Atê $95,0 \mathrm{~kg}$ peso vivo } \\
\hline & $A(\%)$ & $\mathrm{B}(\%)$ & $A(\%)$ & $\mathbf{B}(\%)$ \\
\hline Fuba de milho & 60,8 & 48,8 & 65,8 & 53,8 \\
\hline Polpa citrica peletizada (moida) & - & 15,0 & - & 15,0 \\
\hline Farelo de trigo & 12,0 & 6,0 & 13,0 & 7,0 \\
\hline Farelo de soja & 16,0 & 19,0 & 10,0 & 13,0 \\
\hline Farinha de carne & 4,0 & 4,0 & 4,0 & 4,0 \\
\hline Feno de alfafa & 4,0 & 2,0 & 4,0 & 2,0 \\
\hline Gordura sulna & 2,0 & 4,0 & 2,0 & 4,0 \\
\hline Sal lodado & 0,5 & 0,5 & 0,5 & 0,5 \\
\hline Farinha de ossos & 0,5 & 0,5 & 0,5 & 0,5 \\
\hline Premix & 0,2 & 0,2 & 0,2 & 0,2 \\
\hline
\end{tabular}

A composiçțo quimica das raçōes revelaram à análíse, os dados constantes da Tabela II.

Todas as medidas estudadas foram tomadas nas meia-carcaças direitas. As mensuraçбes foram efetuadas segundo o método brasileiro de classificaçāo de carcaças (MBCC) de acordo com PINHEIRO MACHADO ${ }^{9}$ (1967). Assim, o comprimento da carcaça fol tomado entre o bordo cranial da sinfise pubiana e o bordo cranial da intersecçăo da 1.* costela no esterno; o comprimento da perna lol me dido entre a extremidade do casco e o bordo cranial da sinflise publana; as medidas de espessura do toicinho foram efetuadas (1) na reglăo oposta a primeira vértebra torácica (altura da primeira costela), (2) na posiçăo oposta à Intersecçăa entre a última vértebra torácica e a prímeira lombar, (3) na última vértebra lombar (posiçăo oposta à artículação da penúltima com a última vértebra lombares); a area do olho de lombo fol medida num corte transversal da carcaça, entre a última vértebra torácica e a primeira lombar (porção proximal).

O objetivo deste experimento foi estudar o efeito da substituiçăo parcial do milho pela polpa citrica peletizada e moida (no nivel de $15 \%$ da raç̆o), sobre o desenvolvimento de suínos para engorda e sobre as características das respectivas carcaças. 
VELLOSO, L. et al. - Efelto da substituiço parcial do milho pela polpa citríca peletizada no desenvolvimento e na qualldade da carcaca de sulnos. Rev. Fac. Med. vet. Zootec, Univ. S. Paulo, 11:31-42, 1974.

T A B E L A I I

Composiç̣̂́o química das raçóes.

\begin{tabular}{l|c|c|c|c}
\hline \multirow{2}{*}{ Componentes } & \multicolumn{2}{|c|}{ Fase I } & \multicolumn{2}{c}{ Fase II } \\
\cline { 2 - 5 } & A (\%) & B (\%) & A (\%) & B (\%) \\
\cline { 2 - 5 } & & & & \\
\hline \hline Umidade & 11,5 & 11,0 & 11,2 & 11,7 \\
Extrato Etereo & 5,2 & 5,8 & 4,6 & 6,8 \\
Protelna Bruta & 18,2 & 18,2 & 16,1 & 15,9 \\
Matéría Mineral & 5,5 & 6,0 & 5,0 & 4,5 \\
Matéria Fibrosa & 7,0 & 7,5 & 7,0 & 7,0 \\
Atividade Ureática & 0,02 & 0,10 & 0,04 & 0,08 \\
Cálclo & 0,97 & 1,25 & 0,97 & 1,14 \\
P & 0,70 & 0,65 & 0,70 & 0,68 \\
\hline Energia dlgestivel Kcai/kg & 3.269 & 3.209 & 3.289 & 3.229 \\
(calculada) & & & & \\
\hline
\end{tabular}

RESULTADOS E DISCUSSOES

Os pesos médios inicial e final dos sufnos, foram: Tratamento $A=21,1 \mathrm{~kg}$ e 96,0 kg; Tratamento $B=22,3 \mathrm{~kg}$ e $95,0 \mathrm{~kg}$, res- pectivamente. Durante os 84 dias experimentais, registraram-se os seguintes ganhos em peso, médias dlárias, $\mathrm{A}=0,910 \mathrm{~kg}$ e $B=0,863 \mathrm{~kg}$.

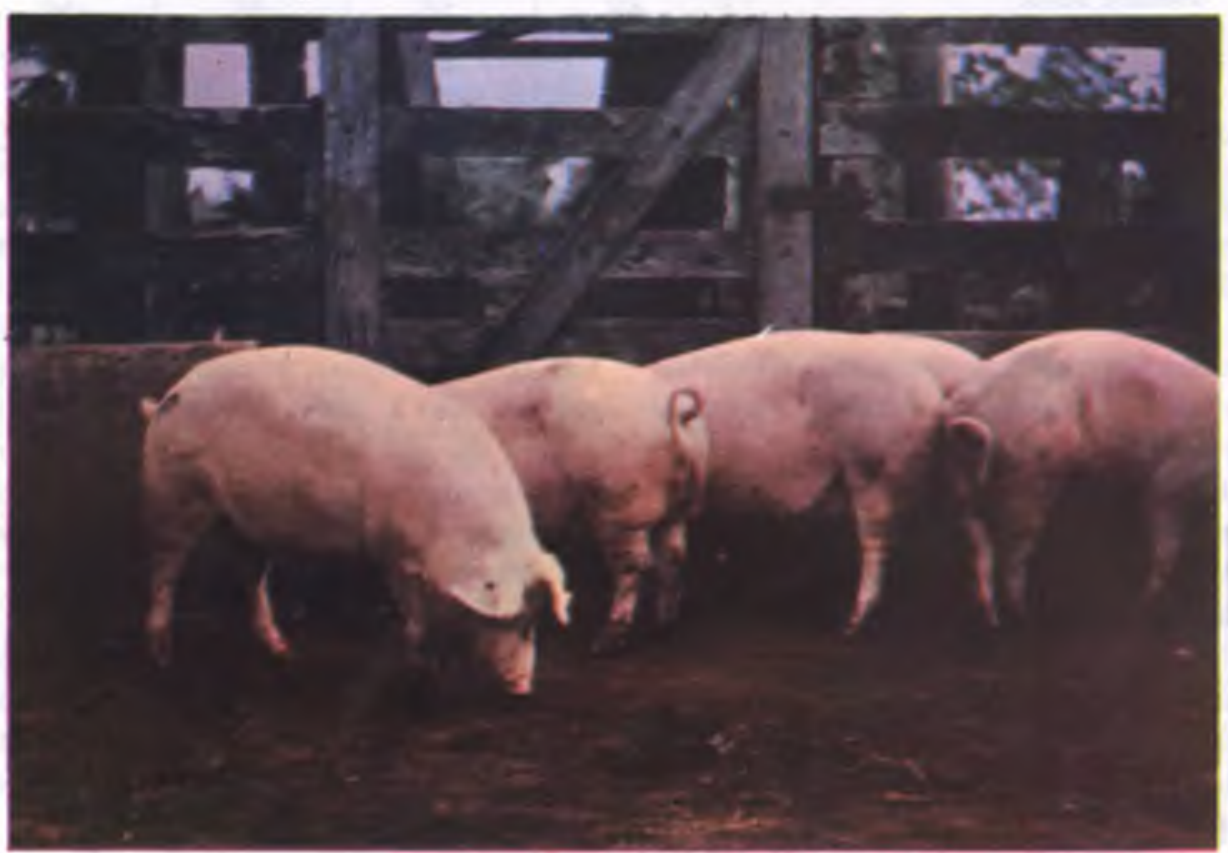

Fig. 1 - Animals do tratamento A $(0 \%$ polpa citrica). 
VELLOSO, L. et al, - Efelto da substituicăo parclal do milho pela polpa citrica peletizada no desenvolvimento e na qualidade da carcaça de suinos. Rev. Fac. Med. vet. Zootec. Univ. S. Paulo, 11:31-42, 1974.

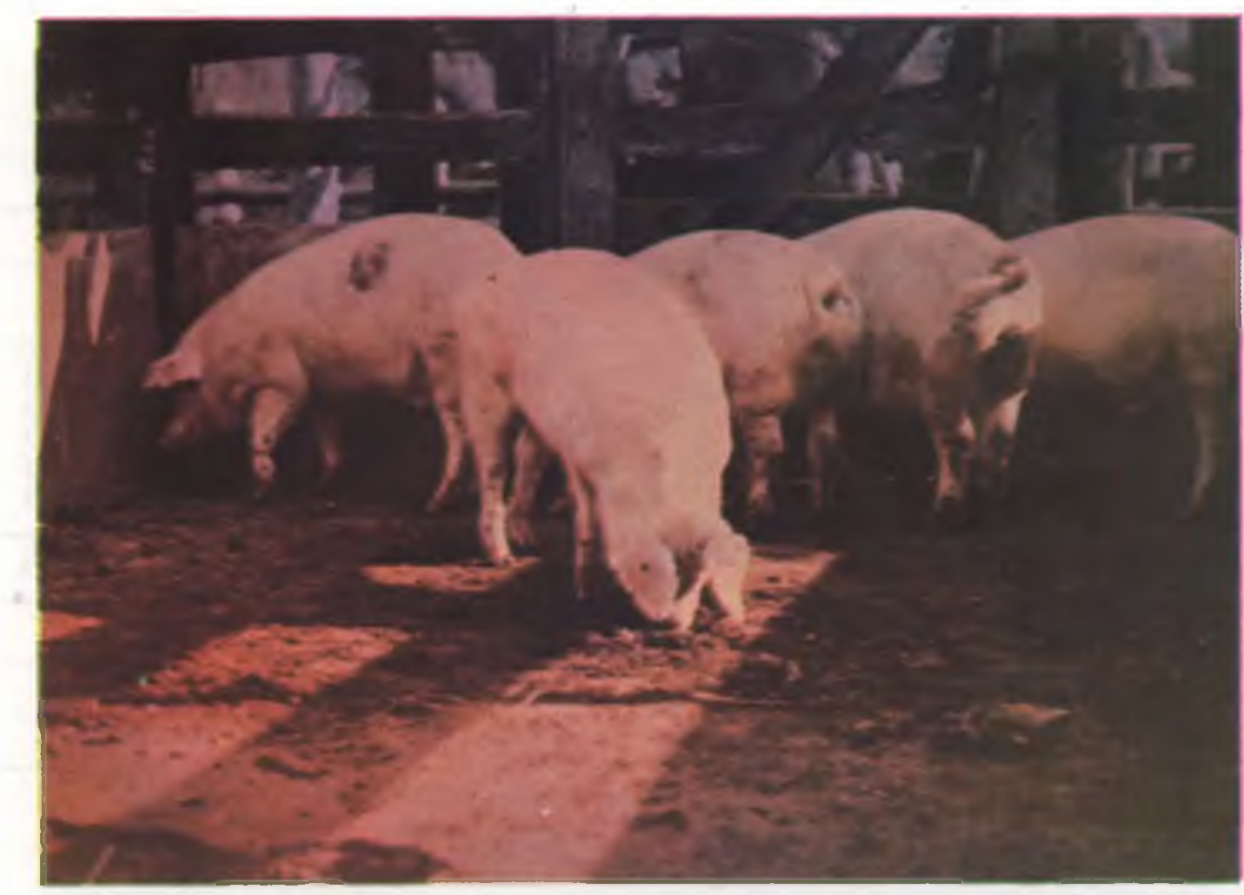

Fig. 2 - Animais do tratamento $B(15 \%$ polpa eitrica $)$.

Os dados referentes aos ganhos em peso. cumulativcs individuais, assim como os de conversāo alimentar, constantes da Tabela III, foram submetidos a análises estatística, sem revelar contudo, diferença significativa ao nivel de $5 \%$ de probabilidade. Os resultados alcançados nestas duas variáveis, sāo superiores àqueles obtidos por BAIRD et al. 3 (1971) e por BAIRD et al. 1 (1972) que trabalharam com a polpa cítrica para suinos, concluindo que até $20 \%$ deste ingrediente, em substituiçāo ao mitho, nāo provocou qualquer efeito negativo na produtividade do animal, tendo inclusive reduzido o custo da produção.

No estudo das carcaças (Figs. 3 e 4), pelo menos sete variáveis foram submetidas a análises estatística. Todas as medidas foram tomadas, seguindo-se as normas do método brasileiro de classificaçāo de car- caças (MBCC), nas $1 / 2$ carcaças direitas, segundo PINHEIRO MACHADO ${ }^{\circ}$ (1967).

Na Tabela IV são exibidos os dados indiviauais de comprimento de carcaças e comprimento de pernas e apenas com relação a esta medida notou-se diferença estatística significativa a $5 \%$ de probabilidade, sendo que o tratamento B (15\% polpa), superou o tratamento A. $(0 \%$ polpa); contudo as médias revelam, que esta diferença só ocorreu em razão da uniformidade dos dados em ambos os tratamentos, nāo sendo portanto motivo para se exaltar. o efeito da polpa citrica.

Estas medidas săo bastante semelhantes àquelas encontradas por KRONKA 7 (1972) para animais da raça Duroc-Jersey, na mesma faixa etária, sendo que os comprmentos das carcaças são superiores aos dados de BAIRD \& AMICK 2 (1966), para 
VELLOSO, L. et al. - Efeito da substituiçáo parcial do milho pela polpa citrica peletizada no desenvolvimento e na qualidade da carcaca de suinos. Rev. Fac. Med. vet. Zootec. Univ. S. Paulo, $11: 31-42,1974$.

T A B E L A I I I

Ganhos em peso, cumulativos individuals e conversăo allmentar, durante 84 dias experimentais.

\begin{tabular}{|c|c|c|c|c|c|c|c|c|}
\hline \multirow{3}{*}{ Blocos } & \multicolumn{4}{|c|}{ Ganhos em peso cumulativos } & \multicolumn{4}{|c|}{ Conversăo alimentar } \\
\hline & \multicolumn{2}{|c|}{$\mathbf{A}$} & \multicolumn{2}{|c|}{$\mathbf{B}$} & \multicolumn{2}{|c|}{ A } & \multicolumn{2}{|c|}{ B } \\
\hline & $\begin{array}{c}\text { Animal } \\
\text { n.॰ }\end{array}$ & $\mathbf{k g}$ & $\underset{\text { n.o }}{\text { Animal }}$ & $\mathbf{k g}$ & $\underset{\text { n. }}{\text { Animal }}$ & $\mathbf{k g}$ & Animal & $\mathbf{k g}$ \\
\hline $\begin{array}{c}\text { I } \\
\text { II } \\
\text { III } \\
\text { IV } \\
\text { V }\end{array}$ & $\begin{array}{r}4 \\
2 \\
6 \\
10 \\
7\end{array}$ & $\begin{array}{l}76,0 \\
81,0 \\
76,0 \\
75,5 \\
70,0\end{array}$ & $\begin{array}{l}3 \\
1 \\
5 \\
9 \\
8\end{array}$ & $\begin{array}{l}73,5 \\
77,0 \\
72,0 \\
67,0 \\
73,0\end{array}$ & $\begin{array}{r}4 \\
2 \\
6 \\
10 \\
7\end{array}$ & $\begin{array}{l}3,20: 1 \\
3,40: 1 \\
3,01: 1 \\
2,83: 1 \\
3,24: 1\end{array}$ & $\begin{array}{l}3 \\
1 \\
5 \\
9 \\
8\end{array}$ & $\begin{array}{l}3,25: 1 \\
3,25: 1 \\
2,96: 1 \\
3,15: 1 \\
2,70: 1\end{array}$ \\
\hline \multirow{3}{*}{$\mathbf{v}$} & Média & 75,7 & Média & 72,5 & Média & $3,16: 1$ & Media & $3,06: 1$ \\
\hline & \multicolumn{4}{|c|}{ C.V. $=3,92 \%$} & \multicolumn{4}{|c|}{ c.V. $=7,15 \%$} \\
\hline & & $S(\hat{m})$ & 1,30 & & & $s(\hat{m})$ & 0,09 & \\
\hline
\end{tabular}

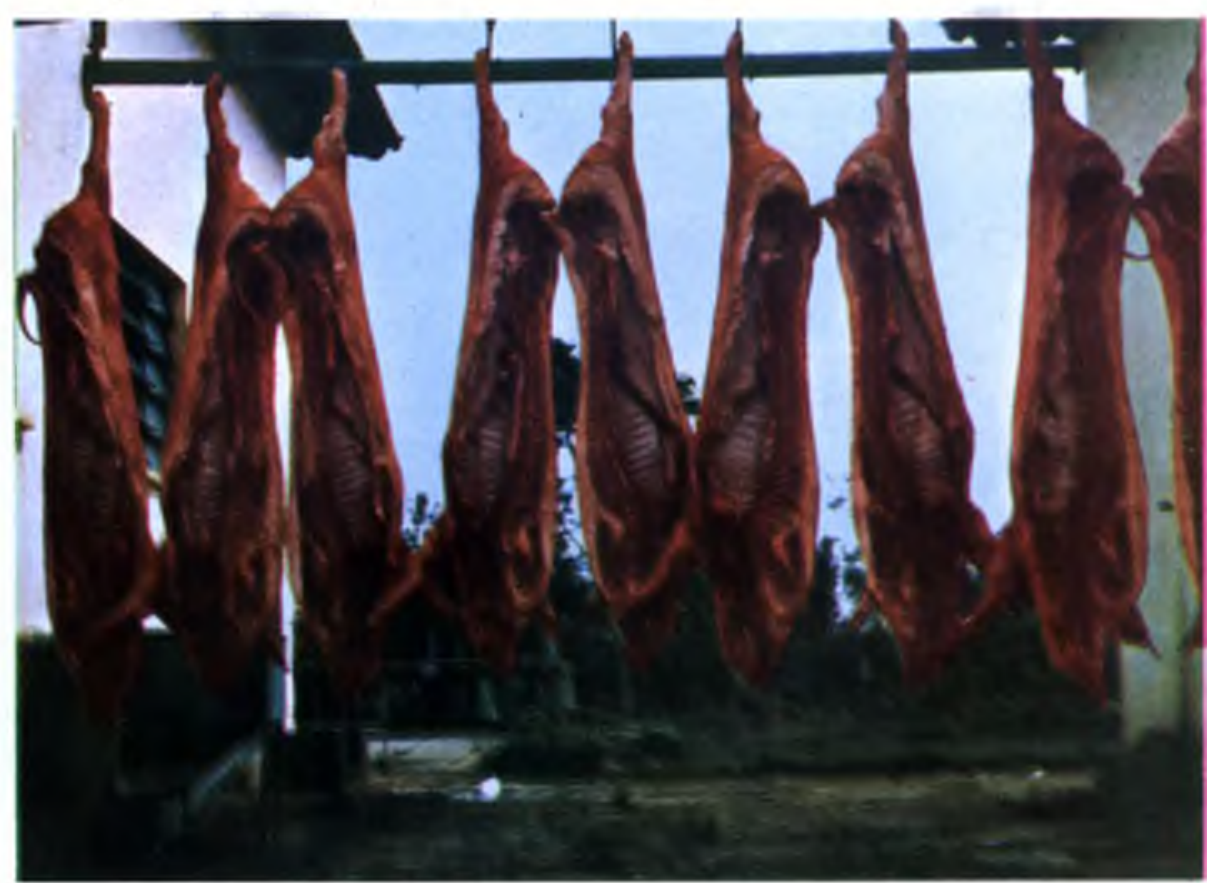

Fig. 3 - Carcacas dos animals do tratamento A. 
VELLOSO, L. et al. - Efeito da substitulça parclal do miliho pela polpa citrica peletizada no desenvolvimento e na qualidade da carcaça de sulnos. Rev. Fac. Med. vet. Zootec. Univ. S. Paulo, 11:31-42, 1974.

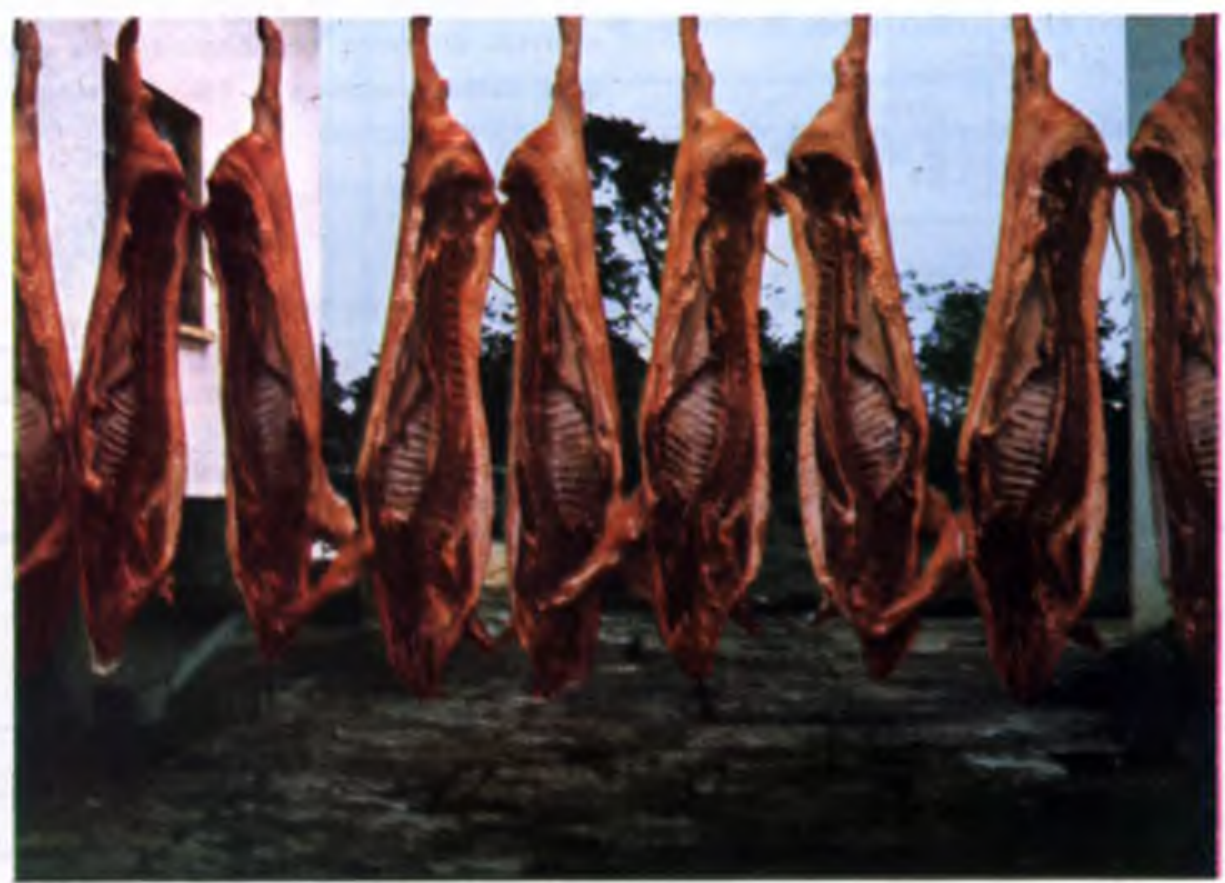

Fig. A - Carcacas dos animals do tratamento B.

T A B EL A I V

Médias dos comprimentos das carcacas e das pernas.

\begin{tabular}{|c|c|c|c|c|c|c|c|c|}
\hline \multirow{3}{*}{ Blocos } & \multicolumn{4}{|c|}{ Comprimento de carcacas } & \multicolumn{4}{|c|}{ Comprimento de pernas } \\
\hline & \multicolumn{2}{|c|}{$\mathbf{A}$} & \multicolumn{2}{|c|}{ B } & \multicolumn{2}{|c|}{ A } & \multicolumn{2}{|c|}{$\mathbf{B}$} \\
\hline & $\begin{array}{c}\text { Animal } \\
\text { n. }\end{array}$ & cm & $\begin{array}{c}\text { Animal } \\
\text { n.0 }\end{array}$ & $\mathrm{cm}$ & $\begin{array}{c}\text { Animal } \\
\text { n. }\end{array}$ & $\mathrm{cm}$ & $\underset{n .0}{\text { Animal }}$ & $\mathrm{cm}$ \\
\hline $\begin{array}{c}\text { I } \\
\text { II } \\
\text { III } \\
\text { IV } \\
\text { V }\end{array}$ & $\begin{array}{r}4 \\
2 \\
6 \\
10 \\
7\end{array}$ & $\begin{array}{l}79,7 \\
79,1 \\
79,1 \\
75,1 \\
73,5\end{array}$ & $\begin{array}{l}3 \\
1 \\
5 \\
9 \\
8\end{array}$ & $\begin{array}{l}80,0 \\
81,0 \\
79,3 \\
76,5 \\
77,2\end{array}$ & $\begin{array}{r}4 \\
2 \\
6 \\
10 \\
7\end{array}$ & $\begin{array}{l}58,2 \\
58,1 \\
56,1 \\
56,6 \\
56,2\end{array}$ & $\begin{array}{l}3 \\
1 \\
5 \\
9 \\
8\end{array}$ & $\begin{array}{l}59,7 \\
59,0 \\
57,1 \\
56,4 \\
57,3\end{array}$ \\
\hline \multirow{3}{*}{$\mathbf{v}$} & Média & 77,3 & Média & 78,8 & Médla & 57,0 & Médla & $\mathbf{5 8 , 1}$ \\
\hline & \multicolumn{4}{|c|}{ c.v. $=1,34 \%$} & \multicolumn{4}{|c|}{ C.v. $=0, \pi 7 \%$} \\
\hline & & $\mathbf{S}(\hat{\mathbf{m}})$ & 0.46 & & & $S(\hat{m})$ & 0,19 & \\
\hline
\end{tabular}


VELLOSO, L. et al. - Efelto da substitulç̃o parclal do milho pela polpa citrica peletızada no desenvolvimento e na qualidade da calcaca de sulnos. Rev. Fac. Med. vet. Zootec. Univ. \$. Paulo, 11:31-42, 1974 .

suinos Polland-China e também superiores aos resultados apresentados por SMITH \& CARPENTER 10 (1973) e por CUNNINGHAM et al. 5 (1973).

As medidas referentes a área do olho de lombo e espessura média do toicinho, são apresentadas na Tabela $V$, năo tendo ocorrido diferença significativa para qualquer destas variáveis a $5 \%$ de probabilidade.

TABELA V

Médlas de área do olho de lombo e espessura do tolcinho.

\begin{tabular}{|c|c|c|c|c|c|c|c|c|}
\hline \multirow{3}{*}{ Blocos } & \multicolumn{4}{|c|}{ Area do olho de lombo } & \multicolumn{4}{|c|}{ Espessura médla do tolcinho } \\
\hline & \multicolumn{2}{|c|}{$\mathbf{A}$} & \multicolumn{2}{|c|}{$\mathbf{B}$} & \multicolumn{2}{|c|}{$\mathbf{A}$} & \multicolumn{2}{|c|}{ B } \\
\hline & Animal & $\mathrm{cm}^{2}$ & $\underset{n .0}{\text { Animal }}$ & $\mathrm{cm}^{3}$ & $\begin{array}{c}\text { Animal } \\
\text { n. }\end{array}$ & $\mathbf{c m}$ & $\begin{array}{c}\text { Animal } \\
\text { n.॰ }\end{array}$ & cm \\
\hline I & 4 & 26,24 & 3 & 21,88 & 4 & 4,53 & 3 & 4,30 \\
\hline II & 2 & 28,56 & 1 & 23,72 & 2 & 4,36 & 1 & 3,83 \\
\hline III & 6 & 22,40 & 5 & 22,20 & 6 & 3,46 & 5 & 3,96 \\
\hline IV & 10 & 25,04 & 9 & 23,72 & 10 & 3,70 & 9 & 2,96 \\
\hline \multirow[t]{4}{*}{$\mathbf{v}$} & 7 & 21,40 & 8 & 25,12 & 7 & 3,60 & 8 & 3,40 \\
\hline & Média & 24.73 & Médla & 23,32 & Média & 3,93 & Médla & 3,69 \\
\hline & \multicolumn{4}{|c|}{ c.v. - $10,26 \%$} & \multicolumn{4}{|c|}{ c.v. - $8,71 \%$} \\
\hline & \multicolumn{4}{|c|}{$\mathbf{S}(\hat{\mathbf{m}})$} & \multicolumn{4}{|c|}{$\mathbf{S}(\hat{m})$} \\
\hline
\end{tabular}

As médias obtidas para área do olho de lombo e espessura de toicinho diferem daquelas observadas por BAIRD \& AMICK ${ }^{2}$ (1966) e por SMITH \& CARPF.NTER 10 (1973). No presente trabalho a área de lombo foi inferior e a espessura do toicinho superior às medidas encontradas por aqueles pesquisadores. Por outro lado há muita semelhança entre os resultados desta investigaçăo e aqueles apresentados por KRONKA ${ }^{\top}$ (1972) e por CUNNINGHAM et al. 5 (1973). Estas comparaçōes tanto podem evidenciar diferenças na composição das raçōes usadas numas e noutras pesquisas, como também podem estar relacionadas com os tipos de animais utilizados.

Na Tabela VI são mostrados os rendimentos das carcaças, rendimentos dos cor- tes cárneos e rendimentos dos tecidos adiposos. Como todos estes parâmetros são expressos em porcentagens, foram os mesmos transformados em arco seno $V^{\top} \mathbf{P} / 100$ para efeito de interpretaçð̄es estatísticas.

Nāo foi detectada diferença significativa para qualquer das variáveis. Visando proporcionar melhor entendimento dos resultados, seguem as médias já transformadas em arco seno $\sqrt{\overline{\mathrm{P} / 100} \text { : rendimento }}$ de carcaça, $\mathrm{A}=62,37$ e $\mathrm{B}=61,40$, com $\mathrm{C} . \mathrm{V} .=2,46 \%$ e $\mathrm{S}(\hat{\mathrm{m}})=0,68$; rendimento dos cortes cárneos, $\mathrm{A}=41,49$ e $\mathrm{B}=43,32$, com C.V. $=2,37 \%$ e $\mathrm{S}(\hat{\mathrm{m}})=0,45$; ren dimento dos tecidos adiposos, $\mathrm{A}=37,57 \mathrm{e}$ $\mathrm{B}=36,37$, com C.V. $=5,16 \%$ e $\mathrm{S}(\hat{\mathrm{m}})=$ 0,85 . 
VELLOSO, L. et al. - Efelto da substitulç̆o parcial do mllho pela polpa citrica peletizada no desenvolvimento e na qualidade da carcaça de sulnos. Rev. Fac. Med. vet. Zootec. Univ. 8. Paulo, 11:31-42, 1974.

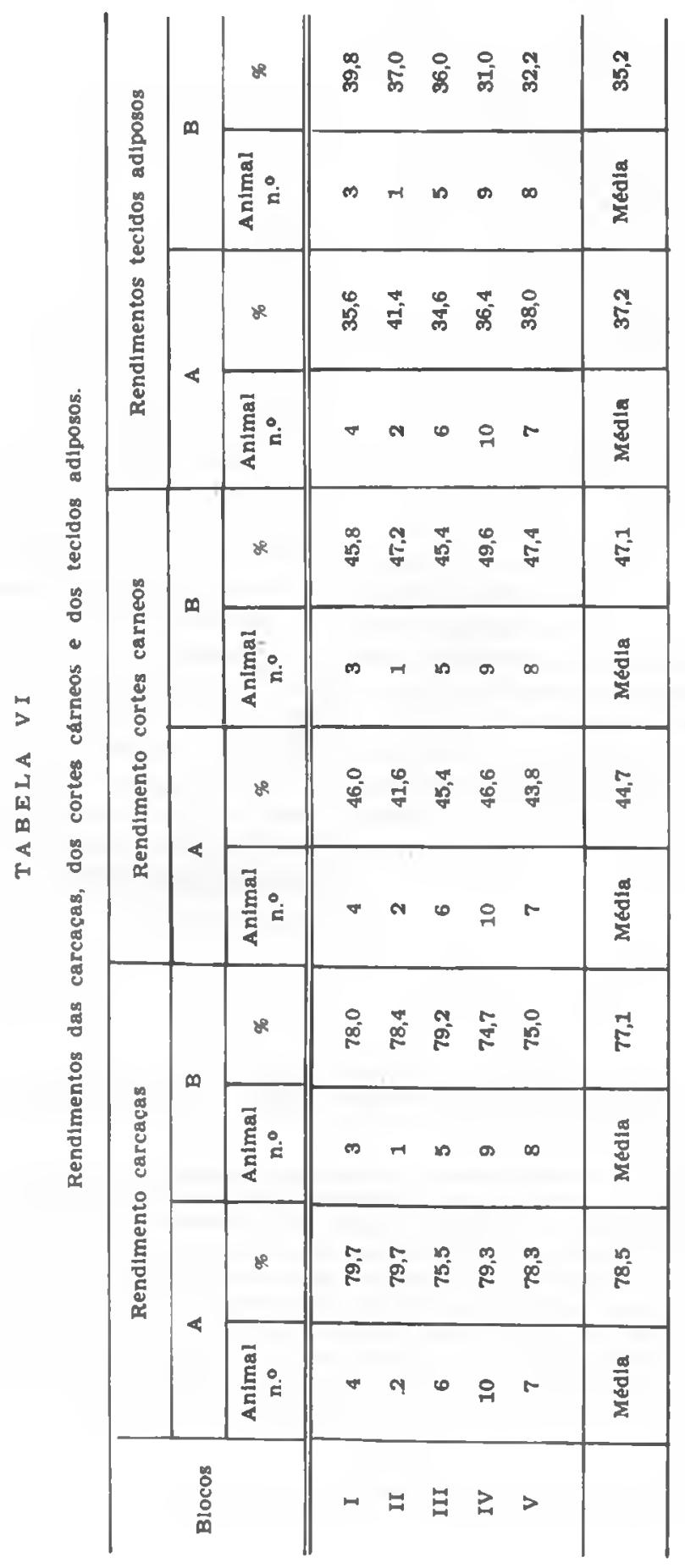


VELLOSO, L. et al. - Efeito da substituicăo parclal do milho pela polpa citrlca peletizada no desenvolvimento e na qualldade da carcaça de sulnos. Rev. Fac. Med. vet. Zootec. Univ S. Paulo, 11:31-42, 1974 .

As medidas de rendimentos percentuais dos cortes cárneos, referem-se à somatória dos pesos da copa, paleta, pernil, lombo e aparas, em relaçăo ao peso das carcaças resfriadas. Os rendimentos dos tecidns adiposos foram estabelecidos entre a somat6ria da banha e do tolcinho também relacionada à carcaça resfriada.

Os rendimentos das carcaças deste experimento são semelhantes aos encontrados por KRONKA ${ }^{7}$ (1972) para suinos machos castrados na mesma faixa de idade e peso. Também há semelhança nos rendimentos dos cortes cárneos, com aqueles revelados por SMITH \& CARPENTER ${ }^{6}$ (1973), notando-se ainda que praticamente todas as medidas apresentadas por estes pesquisadores, com os respectivos desvios padrões, estão em perfeita sintonia com dados da pesquisa aqui apresentada. As medidas dos ganhos em peso ligeiramente mais elevadas neste trabalho, que nos demais citados na revísăo da literatura, săo devidos talvez aos teores de proteína bruta das raçōes utilizadas aqui, terem sido algo mais altos que naqueles experimentos.

\section{CON CLUSOES}

Após serem estabelecidas todas as comparaçóes das variáveis estudadas neste experimento, com iguais parametros apresentados em outros trabalhos realizados com a polpa citrica para suínos ou simplesmente realizados com o objetivo de estabelecer as médias dos diversos cortes das carcaças e, não havendo diferenças marcantes entre os resultados de uma e outras pesquisas, o mesmo ocorrendo com relação aos dois tratamentos desta investígação, concluí-se que há vantagem na utilização da polpa cítrica ao nivel de $15 \%$ nas raçōes para suinos, principalmente quando em substituição a igual teor de milho, pois sendo este um alimento para - homem, estará em maior disponibilidade no mercado. A polpa cítrica peletizada, sem perspectiva de uso como alimento humano, poderá ser transformada em proténa animal de alta qualidade, quando integrando as raçōes dos suínos. Atualmente o custo da polpa cítrica peletizada é mais baixo que o do milho, representando mais uma vantagem para a sua utilização no arraçoamento animal.

\section{RFMV-A/S}

Vexloso, L. et al. - Effect of ground pelleted citrus pulp on swine performance and carcass characteristics. Rov. Fac. Med. vet. Zootec. Univ. S. Paulo, 11:31-42, 1974 .

SUMMARY: Ground pelleted citrus pulp replaced $15 \%$ of corn on rations fed to pigs from 22 to $95 \mathrm{~kg}$. Experiment followed a randomized complete block design with two treatments and five replicates. Average daily gains and feed/gain were: A (0\% citrus pulp) $=.901 \mathrm{~kg}$ and $3.16, B(15 \%$ citrus pulp) $=.86 \mathrm{~kg}$ and 3.06 . No statistical significant differences were noticed. Equally no significant effect was detected for carcass lenght $(\mathrm{cm})$ : $A=77.3$ and $B=78.8$; leg lenght (cm): $A=57.0$ and $B=58.1$; backfat thickness (cm): $A=\$ .93$ and $B=3.69$; loin eye area $\left(\mathrm{cm}^{2}\right)$ : $A=24.75$ and $B=25.32$; dressing $(\%): A=78.5$ and $B=77.1$; lean cuts $(\%): A=44.7$ and $B=47.1$; separable fat $(\%): A-37.2$ and $B=$ s5..2.

UNITERMS: Swines "; Finishing *; Citrus pulp *; Carcass, caracteristics *; t'eeding *. 
VELLOSO, L. et al. - Efelto da substituiçăo parcial do milho pela polpa citrica peletizada no desenvolvimento e na qualidade da carcaça de suinos. Rev. Fac. Med. vet. Zootec. Univ. S. Paulo, 11:31-42, 1974 .

A G R A D E C I M E N T O S

Os autores agradecem as firmas Citrosuco Paulista S.A., Citrobrasil S.A. e Raçōes Fri-Ribe pelas facilidades proporcionadas no desempenho desta pesquisa.

\section{REFERENCIAS BIBLIOGRAFICAS}

1. BAIRD. D. M. et al. - Citrus pulp in swine finishing diets. J. Anim. Sci. :4(2): $348,1972$.

2. BAIRD, D. M. \& AMICK, R. J. - SIX piber sources in equicaloric rationes for finishing hogs. J. Anim. Sci., $25(3): 889,1966$.

3. BAIRD, D. M. et al. - Effect or citrus pulp on ration digestibility and performance of plgs. J. Anim. Sci., 32 (2) : 370, 1971.

4. BAIRD, D. M. et al. - Erfect of fiber source on swine growth and digestibility. J. Anim. Sci., $29(1): 129$, 1969.

5. CUNNINGIIAM et al. - Grain, feed conversion and carcass traits of swine fed under two nutritional reglmes. J. Anim. Sci., 37(1):75-80, 1973.
6. HENDRICKSON, R. \& KESTFRSON, J. W. - By-products of Florida citrus: composition, technology and utilizatlon. Bull. Fla. agric. Exp. Sta., (698) 1965 .

7. KRONKA, R. N. - Gordura bovina na alímentação de suinos e seus efeitos no desenvolvimento, qualidade da carcaça e composicăo quimica do tolcinho. Piracicaba, 1972. [Tese Escola Superior de Agrlcultura "Luiz de Queiroz" da Universidade de São Paulo]

8. NATIONAI, RESEARCH COUNCIL (Estados Unidos) - Nutrient Requirements of swine. 6 ed. Washington, 1968.

9. PINHFiRO MACHADO, L. C. - Os suinos. Porto Alegre, A Granja, 1967. p. $6 \approx 2$.

10. SMITH, G. C. \& CARPENTER, Z. L. Evaluation of factors associated with the composition of pork carcasses. J. Anim. Sci., 36(3):493-9, 1973.

11. STEEL, R. G. D. \& TORRIE, J. H. Principles and procedures of statistics. New York. McGraw-HIll Book Co., 1960 . p. 481.

Recebldo para publícaçāo $\mathrm{cm} \quad 2-8-74$ A provado para publicaçăo em 29-8-74 